\title{
Lakes, rivers and floodplains: Evolving relations
}

\section{Floodplain Lakes Workshop, Fayetteville, USA, 16-19 September 2010}

\author{
Peter Gell ${ }^{1}$, S. Hausmann ${ }^{2}$, R. Hall ${ }^{3}$ and J. Holbrook ${ }^{4}$
}

'Centre for Environmental Management, University of Ballarat, Australia; p.gell@ballarat.edu.au 2Department of Geosciences, University of Arkansas, USA; ${ }^{3}$ Department of Biology, Queens University, Canada; ${ }^{4}$ Department of Geology, University of Texas, Arlington, USA

The evolution of floodplain lakes systems was the theme for a workshop held in Fayetteville, in September 2010. This workshop attracted 30 participants from across the USA, but also from Australia, Russia, Canada, Brazil, and China, with case histories presented from the Murray-Darling, Yangtze, Mississippi and Missouri, Amazon, Rio Manu, Sacramento, White River, Peace-Athabasca and Cauca (Columbia) river systems.

The meeting arose from a gathering at the $3^{\text {rd }}$ PAGES Open Science meeting in Corvallis, Oregon, in 2009 and was set within Focus 4 ("PHAROS") of PAGES, and particularly aligned with the Theme "Water" and the associated Working Groups Human Impacts on Lake Ecosystems (LIMPACS) and Land Use and Climate Impacts on Fluvial Systems (LUCIFS).

The presentations spanned three main themes: proxy and chronological development, regional integration and evidence of human impact. The 20 presentations and seven posters covered evidence of accelerated catchment sediment yields, lead and other metal pollutants, and the response of floodplain wetlands to connectivity to the river, regulation of flow, and alteration to water quality. Situated in the Mississippi Basin, the meeting explored in detail the evolution of meander belts in the Missouri River with climate-driven shifts between meandering and braided states, as evident from dated paleo-wetland sequences (Fig. 1).

Considerable discussion was directed towards the particular challenges that are posed by undertaking paleoenvironmental research in such dynamic systems and the need to develop links between researchers working on the history of these systems. Despite recognition of these challenges, study after study showed that sedimentary profiles provided decipherable and informative records of hydroecological changes, and participants identified that a focus on river-wetland interactions holds considerable promise for addressing scientific and management issues of high societal concern. In particular, capacity was seen to engage with those river authorities that were underpinning policies and management decisions only with shortterm instrumental records. It was also noted that floodplain sites were of cultural significance as many communities live within floodplains and it is often via rivers that humanity experiences climate variability (droughts and floods).

In line with the goals of PHAROS the meeting initiated discussion on regional upscaling of data. This was exemplified by the presentation of a regional synthesis of wetland change from the Murray Darling Basin. This further stimulated the creation of a network of floodplain lake researchers across North America to roll-start the process of assembling a database of geomorphic and paleolimnological research with a view to providing evidence for regional patterns of change and for identifying regions in need of research.

The organizers received considerable interest in response to the call for papers for a special issue of the Journal of Paleolimnology. The participants also made plans for a biannual meeting at which point the community may be in a position to plan for a substantive review output such as an issue in the Developments in PaleoEnvironmental Research (DPER) series. Further, the focus of several projects on RAMSAR (convention on wetlands of international importance) sites (in Australia, Columbia, USA and Brazil) stimulated a proposal for a future activity focussed on exchanging palaeoecological evidence of change with agencies vested with the responsibility of assessing the natural ecological character of listed wetlands and setting limits of acceptable change.

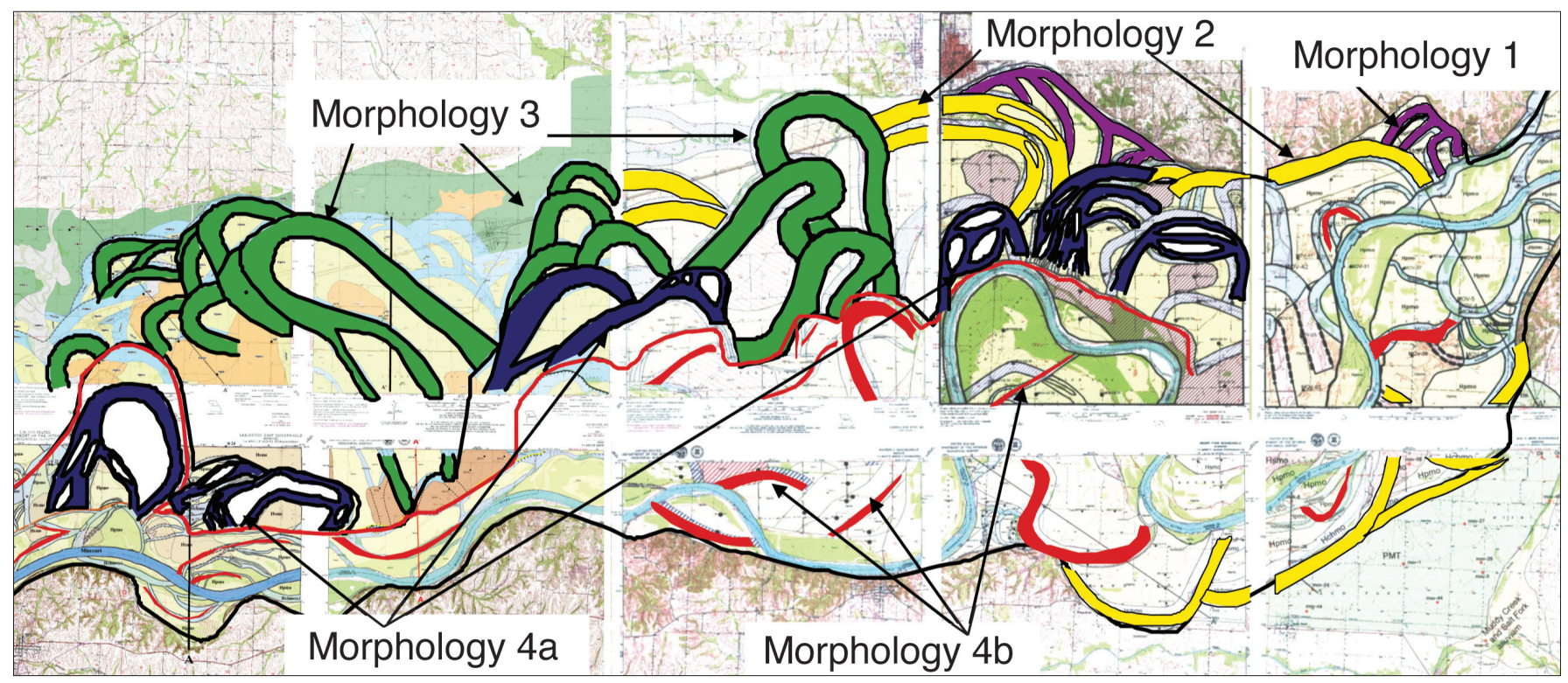

Figure 1: The evolving styles of Missouri River channels. Channel fills older than $3.5 \mathrm{ka}$ BP are highly sinuous with neck cutoffs generating long oxbow lakes. An abrupt climate driven shift in channel shape induced shorter oxbows from lower sinuosity channels, interspersed with sandy islands. From $3.0 \mathrm{ka}$ BP the channels adopted a more braided pattern with few substantive oxbow lakes, with braiding the prevailing state by $1.5 \mathrm{ka}$ BP. The evolving pattern reflects sustained and ongoing increases in the ratio of bedload to discharge. 